\title{
Effect of Some Process Parameters on the Main Properties of Activated Carbon Produced from Peat in a Lab-Scale Process
}

\author{
D. Bergna ${ }^{1,2} \cdot$ T. Hu ${ }^{1} \cdot$ H. Prokkola ${ }^{1} \cdot$ H. Romar ${ }^{1,2} \cdot$ U. Lassi $^{1,2}$
}

Received: 21 March 2018 / Accepted: 3 January 2019 / Published online: 9 January 2019

(c) The Author(s) 2019

\begin{abstract}
Activated carbons (ACs) are widely used in different industrial processes as adsorbents for pollutant removal or as catalytic material support. The parameters and methods of activation can vary, and they affect the final characteristics of ACs, e.g., specific surface area, pore size distribution, and surface functional groups. The results of this study show that microporosity and mesoporosity can be modified, variating these parameters. ACs from Northern Finland Region peat have been prepared through physical activation with steam. The process has been evaluated using the design of experiment approach. Different parameters have been considered as factors, including holding time, oven temperature, heating rate, steam flow, nitrogen flow, kiln rotation, and biomass initial mass. Based on these factors, several responses characterizing the porosity and the elemental analysis of ACs have been selected. All the data collected have been processed statistically using the Fractional Factorial Resolution IV design linear model in a screening configuration fitted with a partial least squares regression using MODDE 9.1 by Umetrics Software.
\end{abstract}

\section{Graphical Abstract}

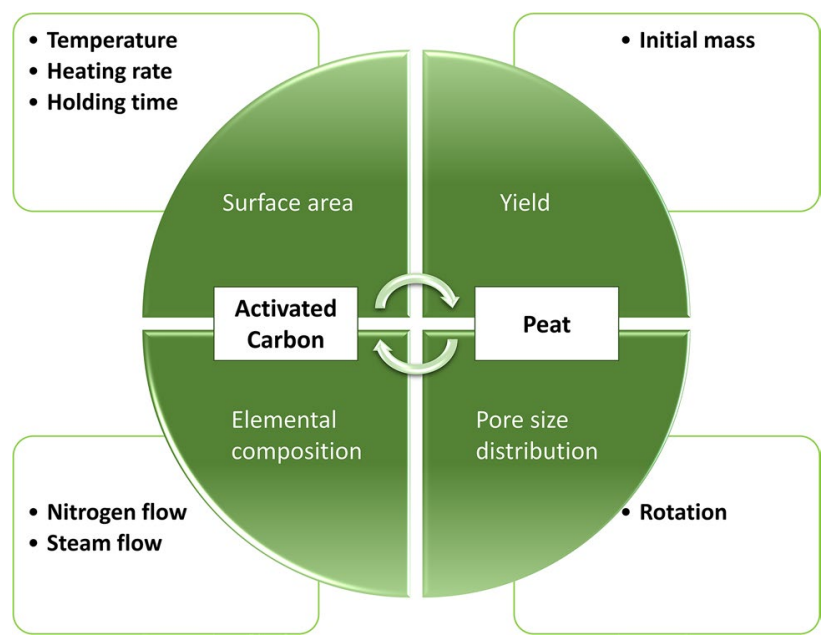

Keywords Activated carbon $\cdot$ Peat $\cdot$ DOE $\cdot$ Pore size distribution $\cdot$ MODDE

D. Bergna

davide.bergna@chydenius.fi

Extended author information available on the last page of the article

\section{Abbreviations}

$\mathrm{AC}$

DOE

DFT

BET

PLS
Activated carbon

Design of the experiment

Density functional theory

Brunauer-Emmet-Teller theory

Partial least square 


$\begin{array}{ll}\text { N } & \text { Number of experiments } \\ \text { DF } & \text { Degrees of freedom } \\ \text { Conf. lev. } & \text { Level of confidence } \\ \text { Cond. No. } & \text { Matrix condition number (unit variance) } \\ \text { SSA } & \text { Specific surface area } \\ \text { PSD } & \text { Pore size distribution } \\ \text { PV } & \text { Pore volume }\end{array}$

\section{Statement of Novelty}

Activated carbons (ACs) can be produced using peat. To produce ACs with task-specific properties, detailed knowledge regarding how different process parameters affect the final properties of the carbons is necessary. The novelty of this study is that the effects of several process parameters on the properties of ACs produced from peat were investigated. Few papers without industry confidential data can be found on this topic. To some extent, the process parameters presented in this paper can be applied to peat-based, industrial-scale AC production, although some additional modifications might be needed for a direct transfer from the lab-scale to the production scale.

\section{Introduction}

Activated carbons (ACs) have a practical interest because they can be used for many different applications. For example, ACs are used for purification applications in different industrial processes, including wastewater treatment, gas cleaning, and metal removal from waste [1-5]. ACs have also been used as support for heterogeneous catalysts or as catalysts [6-11]. The typical properties of ACs include high specific surfaces and well-defined porous structures. The literature provides several definitions of ACs, such as the porosity enclosed by carbon atoms [12]. In general, ACs are defined as carbon atoms bound in structural disorder and discontinuity that allow for porosity.

Furthermore, not only porosity, but also the surface functionality can determine the specificity of ACs $[13,14]$. The consumption and the potential applications of ACs are continuously increasing in the world scale economic prospective [15-20].

To produce ACs, several materials, such as coal and carbon-containing lignocellulosic biomaterials, including industrial waste fractions, (e.g. bark and sawdust), can be used as raw materials. The raw materials are converted through a thermochemical process, creating substances with high carbon content [21-23]. These carbon materials can be further converted into ACs through chemical or physical activation by the addition of activating agents [24-28].
The properties of ACs, such as Specific surface area (SSA), Pore volume (PV), and Pore size distribution (PSD), depend on several parameters, including the raw material, the activation method, and the process parameters used in the carbonization and activation steps. The properties of ACs can be customized according to the final use of the carbons by variations in the process parameters or by specific surface modifications made after production.

There are two main procedures used during the activation process: chemical and physical activation. During physical activation, the carbonized biomass is treated with activation agents, such as water (steam) or carbon dioxide $\left(\mathrm{CO}_{2}\right)$, at temperatures between 700 and $900{ }^{\circ} \mathrm{C}$. During chemical activation, the biomass is impregnated with chemicals, and the activation process is performed at temperatures ranging from 400 to $700{ }^{\circ} \mathrm{C}$. The most common industrial activating agents used are zinc chloride $\left(\mathrm{ZnCl}_{2}\right)$, phosphoric acid $\left(\mathrm{H}_{3} \mathrm{PO}_{4}\right)$, sodium carbonate $\left(\mathrm{Na}_{2} \mathrm{CO}_{3}\right)$ and potassium hydroxide $(\mathrm{KOH})$, but others, such as aluminum chloride $\left(\mathrm{AlCl}_{3}\right)$, magnesium chloride $\left(\mathrm{MgCl}_{2}\right)$, and sodium hydroxide $(\mathrm{NaOH})$, are also used [25, 29, 30]. The mechanism and the operating temperatures of activation depend on the type of chemical agent used. For example, in the case of $\mathrm{ZnCl}_{2}$, the porosity is created by the spaces left by the reactant after washing, while for $\mathrm{KOH}$, the reagent starts the activation process at a higher temperature above $700{ }^{\circ} \mathrm{C}$.

The physical activation advantage mainly consists of a less expensive and greener process: the chemical agents involved $\left(\mathrm{CO}_{2}\right.$, water, or air) are easily available, and the technology is relatively simple and scalable. Chemical activation provides higher yields at the expense of higher process and chemical costs (impregnation, washing, and recovery/disposal of the chemical agent). An economic evaluation, which was not performed for this study, should consider the cost of the starting raw material (e.g., waste/ residues) and the physicochemical characteristics desired in the final product, which play a key role in the selection of the activating method [22].

Physical activation consists of a thermal decomposition of the carbon source material followed by the introduction of an activating agent, typically $\mathrm{CO}_{2}$ or steam [31]. The process is a slow oxidation in which oxygen reacts with the carbon atoms, generating carbon dioxide. This slow oxidation mechanism generates porosity. The oxygen fed into the system is also partially chemisorbed onto the surface, generating oxygen complexes [24].

It has also been demonstrated that $\mathrm{CO}_{2}$ and steam generate different PSDs [32] due to side-produced inhibitors ( $\mathrm{CO}$ in $\mathrm{CO}_{2}$ activation, $\mathrm{H}_{2}$ in steam activation), which enhance microporosity during $\mathrm{CO}_{2}$ activation and mesoporosity during steam activation with the consequent formation of different functional groups. For the $\mathrm{C}-\mathrm{CO}_{2}$ interaction, the following mechanism is present: 
$\mathrm{C}+\mathrm{CO}_{2} \leftrightarrow \mathrm{CO}+\mathrm{C}(\mathrm{O})$

$\mathrm{C}(\mathrm{O}) \leftrightarrow \mathrm{C}-\mathrm{O}$

$\mathrm{C}(\mathrm{O}) \rightarrow \mathrm{CO}$

In Reaction (1), carbon-oxygen complexes are in the first phase created, and they are stable and obstruct the reaction sites, functioning as a retardant (2). Some of the complexes can decompose to $\mathrm{CO}$ (3), leaving a free carbon surface for an additional reaction.

In the case of $\mathrm{C}-\mathrm{H}_{2} \mathrm{O}$, the mechanism is similar:

$\mathrm{C}+\mathrm{H}_{2} \mathrm{O} \leftrightarrow \mathrm{CO}+\mathrm{C}(\mathrm{H})$

$\mathrm{C}(\mathrm{H}) \leftrightarrow \mathrm{C}-\mathrm{H}$

$\mathrm{C}(\mathrm{H}) \rightarrow \mathrm{H}_{2}$

At the beginning of this reaction, $\mathrm{C}-\mathrm{H}$ complexes are formed. Carbon-hydrogen surface complexes are more stable than carbon-oxygen complexes, creating a more intense inhibition for the reaction. These different surface interactions concur to create different behaviors in the activation results $[24,33,34]$.

The physical activation with steam is generally performed at temperatures ranging between 600 and $900{ }^{\circ} \mathrm{C}$ $[35,36]$ with values of heating rates from 5 to $25^{\circ} \mathrm{C} / \mathrm{min}$ [37-39]. Regarding the holding time, previous studies have reported values between 1 and $2 \mathrm{~h}$ [40, 41]. Similar activating conditions have been reported for $\mathrm{CO}_{2}$ activation $[27,42]$ with a generally higher holding time $[34,43$, $44]$ due to the slower oxidation rate.

For the steam activation method used in this study, a one-step activation process, including two main sub-steps, has been performed: in the first step, the peat was carbonized in an inert atmosphere at temperatures between 300 and $400{ }^{\circ} \mathrm{C}$, and in the second step, it was activated at temperatures between 700 and $800{ }^{\circ} \mathrm{C}$ in which steam was fed and porosity was created (activation phase).

Different reactions can simultaneously occur during the steam activation process:

$\mathrm{C}_{\mathrm{x}}\left(\mathrm{H}_{2} \mathrm{O}\right)_{\mathrm{y}} \rightarrow \mathrm{xC}_{(\mathrm{s})}+\mathrm{yH}_{2} \mathrm{O}$

$\mathrm{C}+\mathrm{H}_{2} \mathrm{O} \rightarrow \mathrm{CO}+\mathrm{H}_{2} \quad \Delta \mathrm{H}=31.14 \mathrm{kcal} \mathrm{mol}^{-1}$

$\mathrm{CO}+\mathrm{H}_{2} \mathrm{O} \rightarrow \mathrm{CO}_{2}+\mathrm{H}_{2} \quad \Delta \mathrm{H}=-9.65 \mathrm{kcal} \mathrm{mol}^{-1}$

$\mathrm{C}+\mathrm{CO}_{2} \rightarrow 2 \mathrm{CO} \quad \Delta \mathrm{H}=40.79 \mathrm{kcal} \mathrm{mol}^{-1}$

$\mathrm{C}+2 \mathrm{H}_{2} \rightarrow \mathrm{CH}_{4} \quad \Delta \mathrm{H}=-17.87 \mathrm{kcal} \mathrm{mol}^{-1}$

The temperature affects the gasification reaction (e.g., low reaction temperature $\approx 600{ }^{\circ} \mathrm{C}$ favors the production of $\mathrm{CO}_{2}$, while temperatures higher than $900{ }^{\circ} \mathrm{C}$ favor the production of $\mathrm{CO})[24,45]$.

In the present study, the effects of the variations of several process parameters on the main properties of activated carbons, such as SSA, PV, and PSD, were investigated using peat as the starting material for the process. The peat was carbonized and activated through physical activation by steam in a one-stage process. For this research, the design of experiment (DOE) approach was implemented [46, 47] to follow the principles of green chemistry $[48,49]$.

\section{Materials and Methods}

\section{Biomasses}

In this study, peat from Northern Finland was used. The samples were stored in sealed plastic containers at room temperature before use. The peat was previously sieved to homogenize the material size and was dried overnight at $105{ }^{\circ} \mathrm{C}$ in a mechanical convection oven. The percentage of moisture was calculated as initial mass detracted by dry mass and divided by the initial mass itself. For the raw peat, this value was near $50 \%$ of the total mass, and the drying pretreatment was necessary to reduce the amount of water in the reactor out-stream.

\section{Software}

For the design of the experiment, software MODDE 9.1 by Umetrics was used. In the first step, a Factor List of seven process parameters was selected. The settings criteria provided were selected according to hardware constraints, safety issues, and previous runs.

\section{Carbonization and Steam Activation of Samples- Process Parameters and Identification of Process Factors}

The carbonization and activation of samples were performed as a combined one-step process in a rotating quartz reactor inserted in a tubular oven (Nabertherm $\mathrm{GmbH}$ RSRB 80-750/11). During the carbonization step, the reactor temperature was incremented from room temperature levels to distinct levels of temperature and different ramping times according to the DOE. The atmosphere within the reactor remained inert due to a continuous flushing of protecting gas (nitrogen). When the target temperature was reached, the inert atmosphere was changed into an activating atmosphere by injecting steam (Fig. 1). Following the activation step, the samples were cooled to room temperature in a nitrogen atmosphere overnight and were 
Fig. 1 Peat activation one-step process diagram
One step process activation

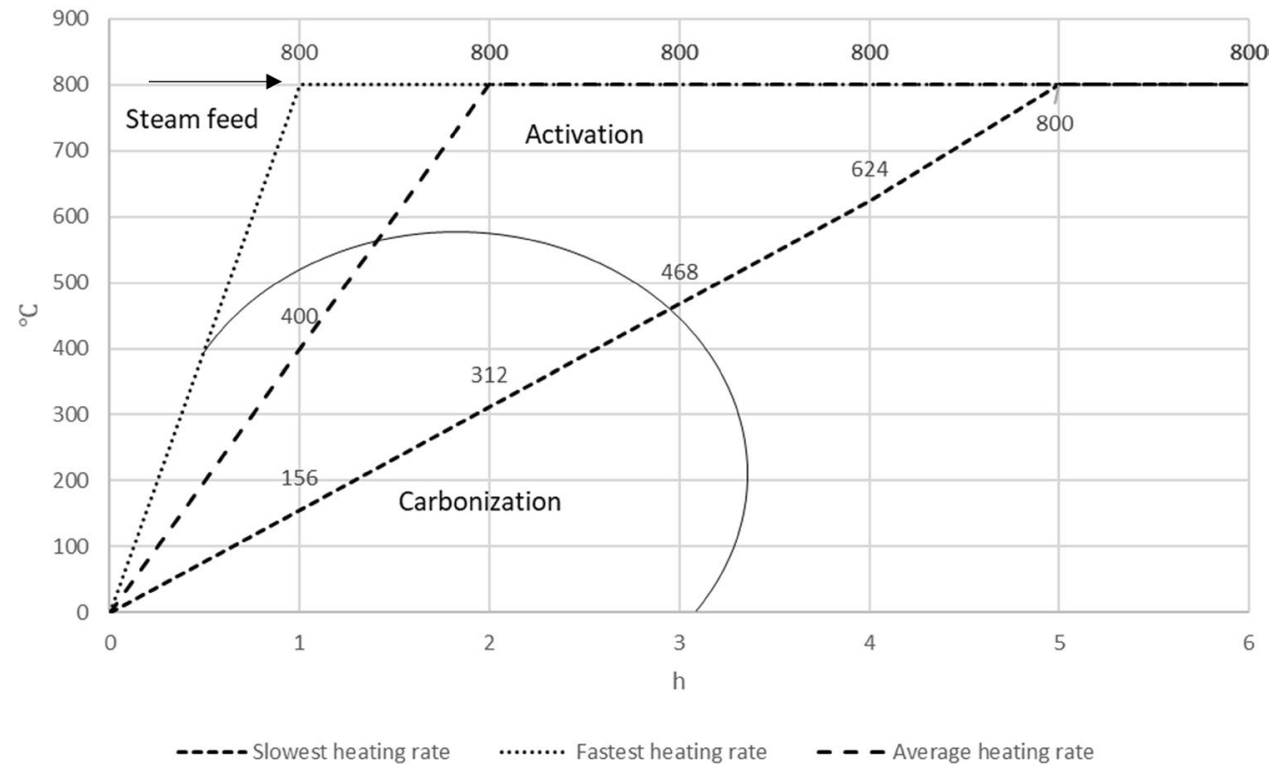

then recovered. A scheme of the one-step activation process is presented in Fig. 2. A mass flow regulator mounted on the input of the reactor tube controlled the flow of the protective gas. The activating gas (steam) was produced in a Controlled Evaporator mixer (Bronkhorst) maintained at $140{ }^{\circ} \mathrm{C}$, and water was fed into the evaporator through a mass flow controller (Bronkhorst). The steam was transferred to the reactor through a heated transfer-line using nitrogen gas as a carrier. The process parameters selected as factors were holding time, oven temperature, heating rate, steam flow, rotation speed, nitrogen flow, and initial mass of biomass used.
Fig. 2 One-step process peat activation with steam set-up scheme 


\section{Characterization of the Carbons Produced- Response List}

The activated carbons were characterized by several methods to investigate the porosity characteristics and the elemental composition of the final product. For porosity, specific SSA (BET), PV, and PSD (DFT) were evaluated. For the elemental analysis, the total carbon, hydrogen, oxygen, and nitrogen contents in the product were considered, with the final yield as further parameter. All the results contributed to creating the response list shown in Table 1.

\section{Generation of the Matrix of Experiments}

The first part of the research involved designing and individuating the parameters necessary for the experiment. The "Screening mode" configuration was chosen as a setup for the matrix generation. From a factor list of seven process parameters, a matrix of the experiment was generated from the software following the fractional factorial resolution IV fitted with the partial least square regression PLS. The number of experiments resulting from the Screening mode was $19\left(2^{(7-3)}+3\right.$ repetitions with intermediate values). The values of the process parameters were specified in a range with a minimum and a maximum value, as reported in Table 1. These values represent the parameters according to which the study was carried out and for which all the analyses achieved statistical validity. The experiments were performed following a random sequence to maintain stochastic independence between each experiment.

\section{Yields, Total Carbon, and Elemental Analysis}

The mass yield from each sample was calculated as the mass of activated carbon divided by the mass of the initial dry sample. The percentage of total carbon present in each sample was measured using the Skalar Primacs MCS instrument. Dried samples were weighted in quartz crucibles and combusted at $1373 \mathrm{~K}$ in a pure oxygen atmosphere, and the formed $\mathrm{CO}_{2}$ was analyzed by an IR analyzer. The carbon content values were obtained by reading the signal of the IR analyzer from a calibration curve derived from known masses of a standard substance, citric acid. The total mass of carbon in each sample was calculated as a percentage of the mass initially weighted.

An elemental analysis was performed with a Flash 2000 CHNS-O Organic elemental analyzer produced by Thermo Scientific. The ground sample was first weighted to $1.5-3.5 \mathrm{mg}$ and dried for $1 \mathrm{~h}$ at $105^{\circ} \mathrm{C}$. Then, the sample was placed in the analyzer and mixed with $10 \mathrm{mg}$ of vanadium pentoxide $\mathrm{V}_{2} \mathrm{O}_{5}$ to enhance burning. The prepared sample was then combusted at a temperature of $960{ }^{\circ} \mathrm{C}$ for $600 \mathrm{~s}$ using as a standard methionine for the hydrogen and nitrogen, while the standard used for oxygen was BBOT 2,5-(Bis(5-tert-butyl-2-benzo-axazol-2-yl) thiophene). Plain tin cups were used as bypasses ( 3 pcs) when beginning the measurements.

\section{Surface Areas and Pore Size Distributions}

SSA and PSD were determined based on the adsorption-desorption isotherms using nitrogen as the adsorbate. The determinations were performed using the Micromeritics ASAP 2020 instrument. Portions of each sample (100-200 mg) were degassed at a low pressure $(2 \mu \mathrm{m} \mathrm{Hg})$ and at a temperature of $413 \mathrm{~K}$ for $2 \mathrm{~h}$ to clean the surfaces and to remove any gas adsorbed. The adsorption isotherms were obtained by immersing sample tubes in liquid nitrogen $(77.15 \mathrm{~K})$ to achieve constant temperature conditions. Gaseous nitrogen was then added to the samples in small doses, and the resulting isotherms were obtained. SSAs were calculated based on the adsorption isotherms according to the Brunauer Emmet Teller (BET) method [50], while nitrogen adsorption and desorption isotherms were used to calculate the PSD using the DFT (Density Functional Theory) [51] algorithm assuming slit-shaped pores. Due to the instrumental setup used, micropores of $1.5 \mathrm{~nm}$ in diameter could be measured. According to the IUPAC notation, the partial volume
Table 1 Factor list of selected process parameters and response list of AC characterization parameters

\begin{tabular}{lllllll}
\hline Factor list & Abb. & Unit & Range & Response List & Abb. & Unit \\
\hline Holding time & Hol & min & 60 to 240 & Yield & Yie & $\%$ \\
Oven temperature & Ove & ${ }^{\circ} \mathrm{C}$ & 700 to 800 & BET surface & BET & $\mathrm{m}^{2} / \mathrm{g}$ \\
Steam flow & Ste & $\mathrm{g} / \mathrm{h}$ & 30 to 120 & Total carbon & TC & $\%$ \\
Heating rate & Heat & ${ }^{\circ} \mathrm{C} / \mathrm{min}$ & 2.6 to 13 & Pore volume BET & Por & $\mathrm{cm}^{3} / \mathrm{g}$ \\
Rotation & Rot & $\mathrm{rpm}$ & 4.36 to 17.44 & DFT micro & $\mathrm{DFT}$ & $\mathrm{cm}^{3} / \mathrm{g}$ \\
Biomass initial mass & Bio & $\mathrm{g}$ & 100 to 300 & DFT meso & $\mathrm{DF} 2$ & $\mathrm{~cm}^{3} / \mathrm{g}$ \\
Nitrogen flow & Nit & $\mathrm{ml} / \mathrm{min}$ & 100 to 300 & DFT total V & DF3 & $\mathrm{cm}^{3} / \mathrm{g}$ \\
& & & & Nitrogen & $\mathrm{N}$ & $\%$ \\
& & & & Hydrogen & $\mathrm{H}$ & $\%$ \\
& & & & Oxygen & $\mathrm{O}$ & $\%$ \\
\hline
\end{tabular}


contributions from micropores $<2 \mathrm{~nm}$, mesopores $2-50 \mathrm{~nm}$, and macropores $>50 \mathrm{~nm}$ were considered and related as a percentage of the total PV.

\section{Results and Discussion}

\section{Variable Importance (VIP) Factors}

The first part of the results includes the evaluation of the main factors of the overall activation process. The VIP values summarize the overall contribution of each variable to the PLS model, summed over all components and weighted according to the response variation accounted for by each component. The level of confidence considered for the results was 95\%. In Fig. 3, an absolute evaluation of the main factors is provided, with holding time, oven temperature, and steam feed being the most influential factors of the overall process. The heating rate in the range considered for this experiment was the least influential factor. The results show that from an industrial perspective, the focus is only the three most influential factors; however, in this study, an analysis of less influential factors was also performed to determine whether these factors had an effect on the final ACs.

The PSD properties and the elemental composition of the ACs produced were analyzed. The empirical results derived from the experiment collected for each sample are reported in Table 2.
For the PSD, a choice between two models was made to provide a commercial comparison (BET) and to analyze the PSD (DFT) more specifically. Based on the results, it can be noted that the BET surface range varied from 5 to about 700 $\left(\mathrm{m}^{2} / \mathrm{g}\right)$ and the total BET PV from 0 to $0.2\left(\mathrm{~cm}^{3} / \mathrm{g}\right)$, while the total PV from DFT ranged from 0.008 to $0.682\left(\mathrm{~cm}^{3} / \mathrm{g}\right)$. The yield showed a variation from 5 to $38 \%$ among the different experiments and a variation in the total carbon from about 29-91.5\%. Based on the elemental composition, the percentage of nitrogen varied from 0 to around $1.5 \%$, the hydrogen from 0.5 to $1.38 \%$, and the oxygen from 1.37 to almost $5 \%$.

\section{Main Effects of the Factors on the Responses and Normalized Coefficients}

In Fig. 4, the different impact factors that the process parameters had on the carbon properties can be observed. The coefficient plot illustrates how a factor affected a selected response. Higher columns indicate a higher impact, and the impact can be either positive or negative. To compare the different coefficients (same scale), they have been normalized, so the coefficient values have been divided by their respective standard deviation. It is immediately evident that holding time and steam feed are the most influential parameters in the PSD responses except for DFT meso. The rotation speed also seemed to have an impact on porosity formation, which was likely due to better contact between the biomass and the activating agent. Thus, considering that the steam activation process is a pore-widening process, an increase
Fig. 3 Variable importance for all the responses on the process

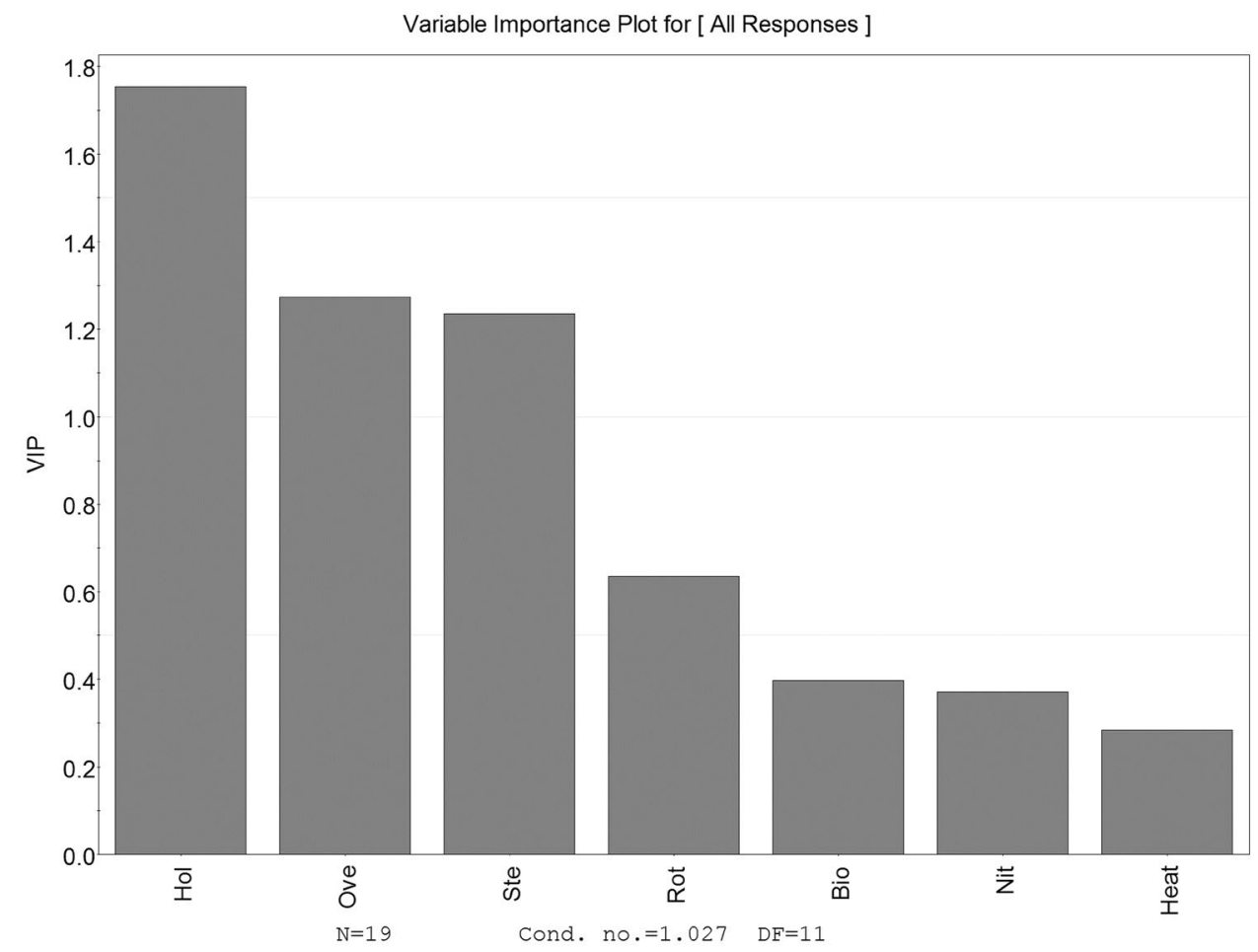




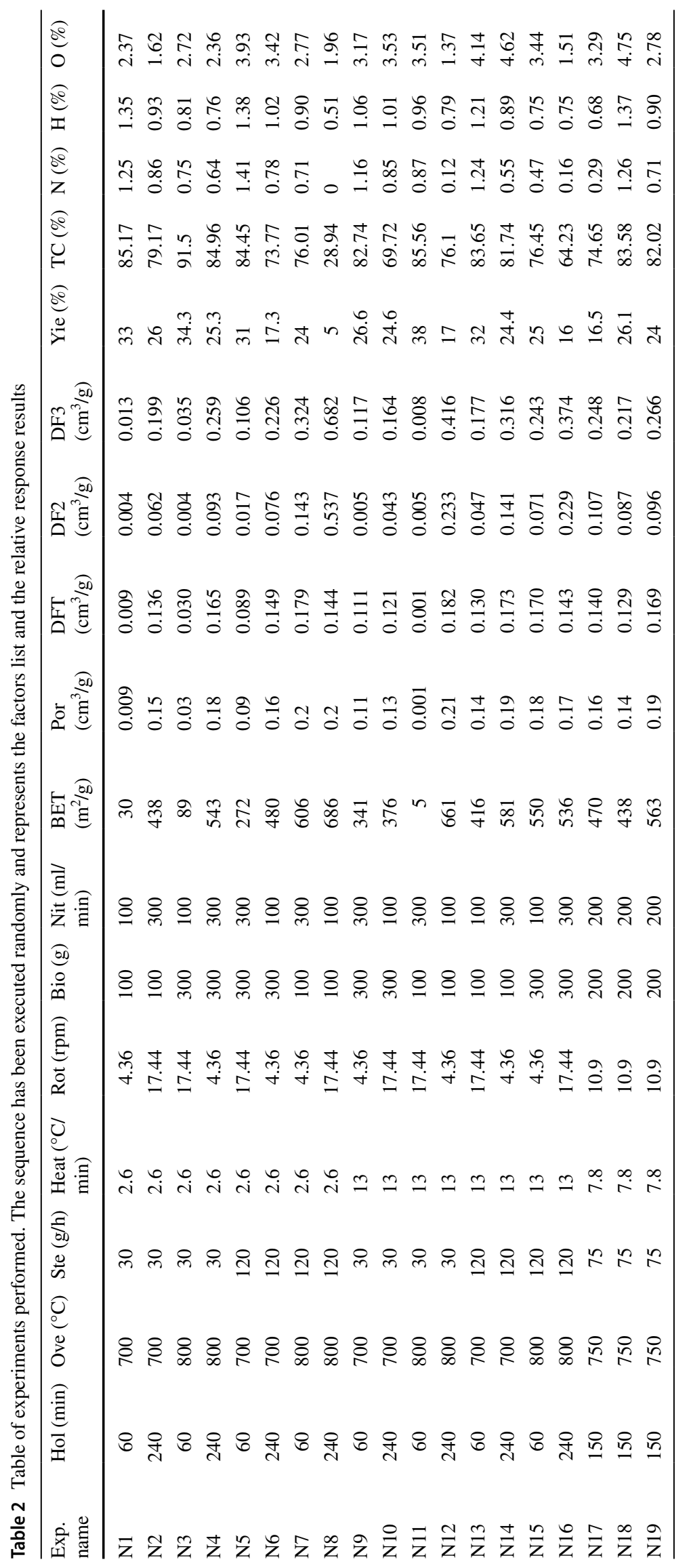




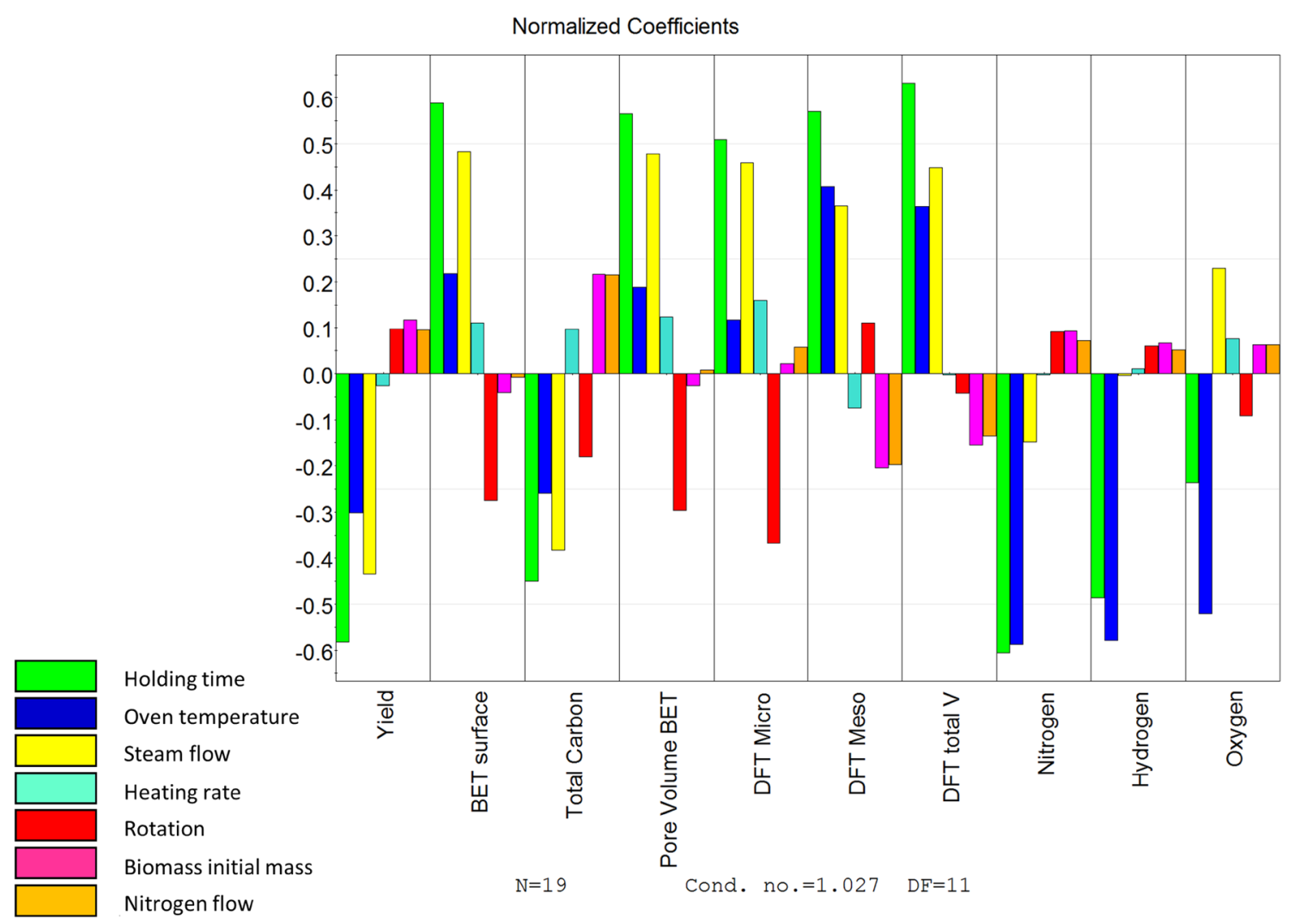

Fig. 4 Normalized coefficient plots indicating the influence of the different process parameters on the pore size distribution and elemental analysis

in rotation speed improved the formation of mesoporosity. The yield was mainly influenced by holding time and steam feed, which was quite intuitive to predict, while it is evident that the initial biomass had a very small effect on the interval selected. This result can be explained by the small mass range difference chosen ( $300 \mathrm{~g}$ and $100 \mathrm{~g})$ as biomass initial mass due to the hardware volume limitation. A stronger scale effect can be expected with higher starting biomass quantities. Another parameter that seemed to have a small effect on the yield is the heating rate. This result suggests that it is possible to avoid an excessively slow heating rate with relative energy consumption to produce a high yield of ACs from peat. For the total carbon, it is shown that holding time and steam feed are the key parameters responsible for the slow oxidation. Evidence of this was observed in sample $\mathrm{N} 8$, where the levels of holding time and steam feed were higher, leaving a low value of carbon that most likely accumulated non-organic materials (ashes). The nitrogen and hydrogen contents seemed to be affected most by the oven temperature and holding time, which is likely due to thermal cracking. At the experimental temperatures considered for this study, there was no evidence of an interaction between nitrogen carrier gas and nitrogen content in the final product. As illustrated by the plot in Fig. 4, the differences in the formation of mesopores and micropores calculated according to the DFT model are clear. In the case of DFT Micro, the main factors were holding time and steam flow, while for DFT Meso, oven temperature also played a key role. By observing the absolute values of this factor, it can be seen that the impact of the parameters in DFT Meso was about two times larger than for DFT Micro. This result suggests a higher time and temperature dependency in the formation of mesopores in a widening mechanism in which microporosity is created first and then while the slow oxidation proceeds, mesopores are produced in a type of "from thin to wide" process. Another aspect to note is the difference in the results when comparing the BET model and the DFT model, which is particularly evident in the total PVs calculated according to the two different theories, although both results indicate that holding time and steam feed are the main factors for porosity production. The heating rate for the experiment considered seemed to have little to no effect on PSD.

\section{Effect of Holding Time}

For the BET surface, a linear increase from 1 to $4 \mathrm{~h}$ was observed that caused a doubling of the BET surface (from 298 to $553 \mathrm{~m}^{2} / \mathrm{g}$ ). The same effect occurs to the pore size 
distribution responses involved with a higher increase in mesopores (from 0.031 to $0.178 \mathrm{~cm}^{3} / \mathrm{g}$ ). This result indicates that the holding time interval was one of the most important parameters in porosity production. The holding time has a decreasing effect on all the elemental analysis responses involved with evidence related to the yield (29.6 to $19.4 \%$ ) and total carbon content (83.4 to $70.7 \%$ ). This result is in accordance with the slow oxidation process in which carbon atoms are converted to $\mathrm{CO}_{2}$ and $\mathrm{CO}$. Nitrogen and hydrogen are strongly reduced by the holding time, while the quantity of oxygen measured showed a smaller decrease in the holding time, suggesting a correlation between the two parameters caused by different thermal decompositions.

\section{Effect of Oven Temperature}

The oven temperature from 700 to $800{ }^{\circ} \mathrm{C}$ slightly increased porosity with a more evident effect on the mesoporosity volume according to the DFT model, which showed a threetime increment (from 0.05 to $0.16 \mathrm{~cm}^{3} / \mathrm{g}$ ) in the $100{ }^{\circ} \mathrm{C}$ interval compared to microporosity. A possible consideration is that the oven temperature influenced the morphology more than the absolute value of PSD. The effect on the responses was evident, particularly in the yield reduction and in the nitrogen content of the final ACs. In the case of oxygen and hydrogen, it seemed that the increasing thermal decomposition due to the relatively high temperature was partially compensated for by the external sources of oxygen and hydrogen from water, which likely formed complexes on the AC surface and were partially adsorbed [24].

\section{Effect of Steam Flow}

Steam flow as the holding time induced a similar effect on PSD with an increase in all the responses and a higher impact on mesopore production $\left(0.054\right.$ to $\left.0.156 \mathrm{~cm}^{3} / \mathrm{g}\right)$. This result demonstrates that physical activation with steam is a widening process in which micropores are generated in the first phase, and in the second phase, mesopores are formed. The steam flow rate had a highly significant effect on the yield and the total carbon and oxygen contents. The oxygen content was positively affected by steam flow (from 2.77 to $3.26 \%$ ), indicating that water "oxygenates" the activated carbon, likely creating functional groups on the surface. Future studies could characterize the type and the variation of these functional groups correlated with the steam feed. The constant value of hydrogen content seemed to be unaffected by the increase in steam flow. This result can most likely be explained by a type of saturation in the quantity of these elements in the ACs that is also correlated with the type of oxidant used (it has been demonstrated that different surface chemistries can be achieved with different activating agents) [52].

\section{Effect of Heating Rate}

The heating rate has an interesting impact on the adsorption properties. The effect was not as relevant when considering the ramping time in the interval used for this experiment, which had a very small influence on porosity production even though the fastest ramping times seemed to slightly favor microporosity. The heating rate had a small effect on all the elemental analysis responses. The yield result is of particular interest: within the heating rate range, no improvement was observed for a slow heating rate; rather, the slow heating rate caused a loss in the final AC yield (23.6 compared to $25.4 \%$ of higher rate). This result suggests that energy and time-consuming ramp $(>1 \mathrm{~h})$ are not beneficial for obtaining higher yields of ACs from peat. A conclusion could be that at the industrial scale, the slow heating rate $<13{ }^{\circ} \mathrm{C} / \mathrm{min}$ used to produce $\mathrm{ACs}$ could be discarded, as it is time and energy consuming. Future studies could investigate faster heating rates $\left(>26^{\circ} \mathrm{C} / \mathrm{min}\right)$ to determine whether this factor induces some effect on porosity. The fastest ramping times seemed to favor the presence of oxygen in the final product, which is likely due to a different thermal decomposition (e.g., slow hydrogen reduction of oxygenating complexes) [53, 54].

\section{Effect of Rotation, Initial Mass, and Nitrogen Flow}

The rotation speed mainly has a negative effect on all the parameters with the notable exception of the mesoporosity formation. This result can be explained by the better efficiency of the interface gas-particle surface interaction along with a parallel mechanical milling stress that changes the final PV. The rotation had a small positive effect on the yield and elemental composition. The total carbon content reduced slightly, which is likely due to better contact within the surface between the peat particles and the steam flow (i.e., higher oxidation). Another interesting finding is that the concentration of oxygen in the final sample seemed to decrease with an increase in speed rotation (from 3.11 to $2.92 \%$ ). For the mass scale considered, the initial biomass mass had no influence or a small influence on the adsorption characteristics of the final activated carbon. This result is in line with the fact that the carbon-steam reaction rate for porosity creation is a gas-surface interaction and not a gas to mass interaction [45]. A possible consideration in this sense could be related to the importance of the reactor design in optimizing contact between the biomass particles and the activating agent. Biomass initial mass was chosen as a factor to determine whether there was a "scale effect" on the quantity of AC carbon produced. The result showed that it is possible to identify a scaling gradient effect that it is in the order of a $1.4 \%$ yield increase in the interval of $100 \mathrm{~g}-300 \mathrm{~g}$ (23.8 to $25.2 \%$ ). Clearly, further investigations 
Table 3 Values of surface area, pore size distribution and elemental analysis related to min and max factor levels (extreme points in the interval)

\begin{tabular}{|c|c|c|c|c|c|c|c|c|c|c|c|}
\hline Fact. Iresp. & $\operatorname{Min} / \max$ & BET $\left(\mathrm{m}^{2} / \mathrm{g}\right)$ & Por $\left(\mathrm{cm}^{3} / \mathrm{g}\right)$ & DFT $\left(\mathrm{cm}^{3} / \mathrm{g}\right)$ & $\mathrm{DF} 2\left(\mathrm{~cm}^{3} / \mathrm{g}\right)$ & $\mathrm{DF} 3\left(\mathrm{~cm}^{3} / \mathrm{g}\right)$ & Yie (\%) & $\mathrm{TC}(\%)$ & $\mathrm{N}(\%)$ & $\mathrm{H}(\%)$ & $\mathrm{O}(\%)$ \\
\hline \multirow[t]{2}{*}{ Hold } & 60 & 297.6 & 0.099 & 0.093 & 0.031 & 0.126 & 29.6 & 83.4 & 0.98 & 1.06 & 3.26 \\
\hline & 240 & 552.9 & 0.178 & 0.156 & 0.178 & 0.335 & 19.4 & 70.7 & 0.50 & 0.84 & 2.76 \\
\hline \multirow[t]{2}{*}{ Ove } & 700 & 381.0 & 0.127 & 0.119 & 0.050 & 0.169 & 26.7 & 80.3 & 1.02 & 1.11 & 3.56 \\
\hline & 800 & 469.5 & 0.150 & 0.130 & 0.160 & 0.292 & 22.3 & 73.3 & 0.46 & 0.79 & 2.46 \\
\hline \multirow[t]{2}{*}{ Ste } & 30 & 324.1 & 0.107 & 0.099 & 0.054 & 0.154 & 27.8 & 82.3 & 0.82 & 0.96 & 2.77 \\
\hline & 120 & 526.4 & 0.170 & 0.150 & 0.156 & 0.307 & 21.2 & 71.8 & 0.65 & 0.94 & 3.26 \\
\hline \multirow[t]{2}{*}{ Heat } & 2.6 & 402.8 & 0.131 & 0.116 & 0.111 & 0.228 & 23.6 & 75.6 & 0.79 & 0.97 & 2.93 \\
\hline & 13 & 447.8 & 0.146 & 0.133 & 0.099 & 0.233 & 25.4 & 78.4 & 0.69 & 0.93 & 3.09 \\
\hline \multirow[t]{2}{*}{ Rot } & 4.36 & 483.4 & 0.159 & 0.146 & 0.089 & 0.236 & 23.2 & 79.5 & 0.72 & 0.94 & 3.11 \\
\hline & 17.44 & 367.1 & 0.118 & 0.103 & 0.121 & 0.225 & 25.8 & 74.6 & 0.76 & 0.96 & 2.92 \\
\hline \multirow[t]{2}{*}{ Bio } & 100 & 436.1 & 0.141 & 0.124 & 0.134 & 0.259 & 23.8 & 73.8 & 0.70 & 0.94 & 2.95 \\
\hline & 300 & 414.4 & 0.136 & 0.125 & 0.076 & 0.202 & 25.2 & 80.3 & 0.78 & 0.96 & 3.08 \\
\hline \multirow[t]{2}{*}{ Nit } & 100 & 425.2 & 0.137 & 0.121 & 0.130 & 0.252 & 23.5 & 74.2 & 0.71 & 0.93 & 2.95 \\
\hline & 300 & 425.3 & 0.140 & 0.128 & 0.080 & 0.209 & 25.5 & 79.9 & 0.78 & 0.97 & 3.08 \\
\hline
\end{tabular}

in this direction should scale up the mass range, which was limited in this study due to the hardware size. Inert gas flow (nitrogen) is another parameter that was investigated. Nitrogen did not affect the porosity parameters except for a slight reduction in mesopore formation. This is likely due to a higher dilution effect on the activating agent with less contact efficiency subsequently between the gas and the biomass surface. Regarding the elemental analysis, the nitrogen flow rate was selected as a factor to determine whether the element could interact with the final product at a relatively high temperature. Based on the quantity of nitrogen detected in the sample for the process parameters applied for this study, no interaction between the gas and the sample was observed. A better yield was achieved with a higher nitrogen flow (23.5 to $25.5 \%$ ). This result suggests that a higher protective atmosphere can "smoothen" the oxidation process. Table 3 provides an overall overview of the minimum and maximum values calculated in the intervals of the respective factors. For example, it is shown that steam flow, holding time, and oven temperature had significant impacts on mesoporosity formation. Other parameters had little to no effect on porosity formation, although the heating rate seemed to have a small effect on PSD.

\section{Conclusions}

In this study, ACs were produced from peat, and the effect of the process parameters on the properties of the ACs produced, including specific surface area, pore size distribution, and elemental compositions, were investigated. The results obtained in this research indicate that it is possible to produce ACs with tailor-made properties (SSA and PSD) starting from peat by a choice of proper process parameters.
A direct transfer of the parameters to an industrial scale production is, however, out of the scope for this research.

The results showed that there is a correlation between the main factors (holding time, oven temperature, and steam flow) and the pore size distribution, suggesting a "widening" mechanism from micropores to mesopores. Furthermore, regarding elemental composition, it seems that a fast heating rate and a high steam flow increase the level of oxygen in the carbon. The nitrogen flow does not influence the nitrogen content in the final AC. The small effect of heating rate on the overall process in the range selected for this study indicates that a fast, one-step activation to avoid time and energy consuming low heating rate is preferable for producing ACs.

Acknowledgements Open access funding provided by University of Oulu including Oulu University Hospital. Davide Bergna acknowledges Central Ostrobothnia Cultural Foundation for a personal grant. KeskiPohjanmaan Rahasto.

\section{Compliance with Ethical Standards}

Conflict of interest The authors declare no conflict of interests.

Open Access This article is distributed under the terms of the Creative Commons Attribution 4.0 International License (http://creativeco mmons.org/licenses/by/4.0/), which permits unrestricted use, distribution, and reproduction in any medium, provided you give appropriate credit to the original author(s) and the source, provide a link to the Creative Commons license, and indicate if changes were made.

\section{References}

1. Marsh, H., Rodríguez-Reinoso, F., Marsh, H., Rodríguez-Reinoso, F.: CHAPTER 8-applicability of activated carbon. In: Activated carbon, Universidad de Alicante, Alicante (2006) 
2. Toles, C.A., Marshall, W.E., Johns, M.M.: Phosphoric acid activation of nutshells for metals and organic remediation: Process optimization. J. Chem. Technol. Biotechnol. (1998). https://doi. org/10.1002/(SICI)1097-4660(199807)72:3\%3C255::AID-JCTB8 90\%3E3.0.CO;2-P

3. Treviño-Cordero, H., Juárez-Aguilar, L.G., Mendoza-Castillo, D.I., Hernández-Montoya, V., Bonilla-Petriciolet, A., MontesMorán, M.A.: Synthesis and adsorption properties of activated carbons from biomass of Prunus domestica and Jacaranda mimosifolia for the removal of heavy metals and dyes from water. Ind. Crops Prod. (2013). https://doi.org/10.1016/j.indcrop.2012.05.029

4. Sharma, Y.C., Uma Gode, F.: Engineering data for optimization of preparation of activated carbon from an economically viable material. J. Chem. Eng. Data (2010). https://doi.org/10.1021/ je100041x

5. Tran, H.N., You, S.J., Hosseini-Bandegharaei, A., Chao, H.P.: Mistakes and inconsistencies regarding adsorption of contaminants from aqueous solutions: a critical review. Water Res. 120, 88-116 (2017)

6. Lahti, R., Bergna, D., Romar, H., Hu, T., Comazzi, A., Pirola, C., Bianchi, C.L., Lassi, U.: Characterization of cobalt catalysts on biomass-derived carbon supports. Top. Catal. (2017). https://doi. org/10.1007/s11244-017-0823-z

7. Prati, L., Bergna, D., Villa, A., Spontoni, P., Bianchi, C.L., Hu, T., Romar, H., Lassi, U.: Carbons from second generation biomass as sustainable supports for catalytic systems. Catal. Today (2016). https://doi.org/10.1016/j.cattod.2017.03.007

8. Bashkova, S., Baker, F.S., Wu, X., Armstrong, T.R., Schwartz, V.: Activated carbon catalyst for selective oxidation of hydrogen sulphide: On the influence of pore structure, surface characteristics, and catalytically-active nitrogen. Carbon N. Y. (2007). https ://doi.org/10.1016/j.carbon.2007.01.005

9. Figueiredo, J.L., Pereira, M.F.R.: The role of surface chemistry in catalysis with carbons. Catal. Today (2010). https://doi. org/10.1016/j.cattod.2009.04.010

10. Lee, J., Kim, K.H., Kwon, E.E.: Biochar as a Catalyst. Renew Sust Energy Rev 77, 70-9 (2017)

11. Lam, E., Luong, J.H.T.: Carbon materials as catalyst supports and catalysts in the transformation of biomass to fuels and chemicals. ACS Catal. 4(10), 3393-410 (2014)

12. Marsh, H., Rodríguez-Reinoso, F.: Activated carbon. Elsevier, New York (2006)

13. Tessmer, C.H., Vidic, R.D., Uranowski, L.I.: Impact of oxygen-containing surface functional groups on activated carbon adsorption of phenols. Environ. Sci. Technol. (1997). https://doi. org/10.1021/es960474r

14. Georgakis, M., Stavropoulos, G., Sakellaropoulos, G.P.: Molecular dynamics study of hydrogen adsorption in carbonaceous microporous materials and the effect of oxygen functional groups. Int. J. Hydrogen Energy. (2007). https://doi.org/10.1016/j.ijhyd ene.2006.08.040

15. Lodewyckx, P.: Chap. 10 Adsorption of chemical warfare agents. In: Activated carbon surfaces in environmental remediation, Elsevier, New York (2006)

16. Giraudet, S., Le Cloirec, P.: Activated carbon filters for filtrationadsorption. In: Activated Carbon Fiber and Textiles, Elsevier, New York (2016)

17. Oubagaranadin, J.U.K., Murthy, Z.V.P.: Activated carbons: Classifications, properties and applications. In: Activated Carbon: Classifications, Properties and Applications, Elsevier, New York (2011)

18. Kalyani, P., Anitha, A.: Biomass carbon \& its prospects in electrochemical energy systems, Elsevier, New York (2013)

19. Li, W., Ding, Y., Zhang, W., Shu, Y., Zhang, L., Yang, F., Shen, Y.: Lignocellulosic biomass for ethanol production and preparation of activated carbon applied for supercapacitor. J. Taiwan Inst. Chem. Eng. (2016). https://doi.org/10.1016/j.jtice.2016.04.010

20. González-García, P.: Activated carbon from lignocellulosics precursors: A review of the synthesis methods, characterization techniques and applications. Renew. Sustain. Energy Rev. 82, 1393-414 (2018)

21. Lewicka, K.: Activated carbons prepared from hazelnut shells, walnut shells and peanut shells for high $\mathrm{CO}_{2}$ adsorption. Polish $\mathrm{J}$. Chem. Technol. (2017). https://doi.org/10.1515/pjct-2017-0025

22. Ioannidou, O., Zabaniotou, A.: Agricultural residues as precursors for activated carbon production-a review. Renew. Sustain. Energy Rev. (2007). https://doi.org/10.1016/j.rser.2006.03.013

23. Roman, S., Gonzalez, J.F., Gonzalez-Garcia, C.M., Zamora, F. Control of pore development during $\mathrm{CO}_{2}$ and steam activation of olive stones. Fuel Process. Technol. 89, 715-720 (2008). https:// doi.org/10.1016/j.fuproc.2007.12.015

24. Marsh, H., Rodríguez-Reinoso, F.: Activation Processes (Thermal or Physical). Act. Carbon. (2006). https://doi.org/10.1016/B978008044463-5/50019-4

25. Marsh, H., Rodríguez-Reinoso, F.: Activation processes (Chemical). Act. Carbon. (2006). https://doi.org/10.1016/B978-00804 4463-5/50020-0

26. Kirubakaran, C.J., Krishnaiah, K., Seshadri, S.K.: Experimental study of the production of activated carbon from coconut shells in a fluidized bed reactor. Ind. Eng. Chem. Res. (1991). https:// doi.org/10.1021/ie00059a008

27. Yang, K., Peng, J., Xia, H., Zhang, L., Srinivasakannan, C., Guo, S.: Textural characteristics of activated carbon by single step $\mathrm{CO}_{2}$ activation from coconut shells. J. Taiwan Inst. Chem. Eng. (2010). https://doi.org/10.1016/j.jtice.2009.09.004

28. Guo, S., Peng, J., Li, W., Yang, K., Zhang, L., Zhang, S., Xia, $\mathrm{H}$.: Effects of $\mathrm{CO}_{2}$ activation on porous structures of coconut shell-based activated carbons. Appl. Surf. Sci. (2009). https:// doi.org/10.1016/j.apsusc.2009.05.150

29. Xu, B., Chen, Y., Wei, G., Cao, G., Zhang, H., Yang, Y.: Activated carbon with high capacitance prepared by $\mathrm{NaOH}$ activation for supercapacitors. Mater. Chem. Phys. (2010). https://doi. org/10.1016/j.matchemphys.2010.07.002

30. Selvanathan, N., Subki, N.S.: Dye adsorbent by pineapple activated carbon: $\mathrm{H}_{3} \mathrm{PO}_{4}$ and $\mathrm{NaOH}$ activation. ARPN J. Eng. Appl. Sci. 10, 20 (2015)

31. Mohamad Nor, N., Lau, L.C., Lee, K.T., Mohamed, A.R.: Synthesis of activated carbon from lignocellulosic biomass and its applications in air pollution control-a review. J. Environ. Chem. Eng. (2013). https://doi.org/10.1016/j.jece.2013.09.017

32. Wigmans, T.: Industrial aspects of production and use of activated carbons. Carbon N. Y. (1989). https://doi.org/10.1016/00086223(89)90152-8

33. Karaman, I., Yagmur, E., Banford, A., Aktas, Z.: The effect of process parameters on the carbon dioxide based production of activated carbon from lignite in a rotary reactor. Fuel Process. Technol. (2014). doi:https://doi.org/10.1016/j.fuproc.2013.07.021

34. Rodríguez-Reinoso, F., Molina-Sabio, M., González, M.T.: The use of steam and $\mathrm{CO}_{2}$ as activating agents in the preparation of activated carbons. Carbon N. Y. (1995). https://doi. org/10.1016/0008-6223(94)00100-E

35. Zanzi, R., Bai, X., Capdevila, P., Björnbom, E.: Pyrolysis of biomass in presence of steam for preparation of activated carbon, liquid and gaseous products. In: Proceedings of 6th world congress on chemical engineering, Melbourne, Australia (2001)

36. Baçaoui, A., Yaacoubi, A., Dahbi, A., Bennouna, C., Tan Luu, P., Maldonado-Hodar, R., Rivera-Utrilla, F.J., Moreno-Castilla, J.: C.: Optimization of conditions for the preparation of activated carbons from olive-waste cakes. Carbon N. Y. (2001). https://doi. org/10.1016/S0008-6223(00)00135-4 
37. Schröder, E., Thomauske, K., Weber, C., Hornung, A., Tumiatti, V.: Experiments on the generation of activated carbon from biomass. J. Anal. Appl. Pyrolysis. (2007). https://doi.org/10.1016/j. jaap.2006.10.015

38. Devnarain, P.B., Arnold, D.R., Davis, S.B.: Production of Activated Carbon from South African Sugarcane Bagasse. In: Proceedings Congress South African Sugar Technologist Association (2002)

39. Faramarzi, A.H., Kaghazchi, T., Ebrahim, H.A., Ebrahimi, A.A.: Experimental investigation and mathematical modeling of physical activated carbon preparation from pistachio shell. J. Anal. Appl. Pyrolysis. (2015). https://doi.org/10.1016/j. jaap.2015.05.012

40. Sun, K., Jiang, J.: Preparation and characterization of activated carbon from rubber-seed shell by physical activation with steam. Biomass Bioenerg. (2010). https://doi.org/10.1016/j.biomb ioe.2009.12.020

41. González, J.F., Román, S., González-García, C.M., Nabais, J.M.V., Ortiz, A.L.: Porosity development in activated carbons prepared from walnut shells by carbon dioxide or steam activation. Ind. Eng. Chem. Res. (2009). https://doi.org/10.1021/ie801848x

42. Mazlan, M.A.F., Uemura, Y., Yusup, S., Elhassan, F., Uddin, A., Hiwada, A., Demiya, M.: Activated carbon from rubber wood sawdust by carbon dioxide activation. Proc. Eng. 148, 530-7 (2016)

43. Wu, M., Guo, Q., Fu, G.: Preparation and characteristics of medicinal activated carbon powders by $\mathrm{CO}_{2}$ activation of peanut shells. Powder Technol. (2013). https://doi.org/10.1016/j.powte c.2013.07.013

44. Sánchez, A.R., Elguézabal, A.A., De La Torre Saenz, L.: CO2 activation of char from Quercus agrifolia wood waste. Carbon $\mathrm{N}$. Y. (2001). https://doi.org/10.1016/S0008-6223(00)00253-0
45. Klei, H.E., Sahagian, J., Sundstrom, D.W.: Kinetics of the activated carbon-steam reaction. Ind. Eng. Chem. Process Design Dev. 14(4), 470-3 (1975)

46. Leardi, R.: Experimental design in chemistry: a tutorial. Anal Chim Acta. 652(1-2):161-72 (2009)

47. Montgomery, D.C.: Design of experiment with several factors. In: Design of experiment with several factors (2014)

48. Anastas, P., Eghbali, N.: Green chemistry: principles and practice. Chem. Rev. (2010). https://doi.org/10.1039/b918763b

49. Clark, H., Clark, J.: J.H.: Green chemistry: challenges and opportunities. Green Chem. (1999). https://doi.org/10.1039/A807961G

50. Brunauer, S., Emmett, P.H., Teller, E.: Adsorption of gases in multimolecular layers. J. Am. Chem. Soc. Volume. 60, 309 (1938). https://doi.org/10.1021/ja01269a023

51. Hohenberg, P.: and W.K.: Density functional theory. Phys. Rev. B. $76(8): 1212(1964)$

52. Jaramillo, J., Álvarez, P.M., Gómez-Serrano, V.: Oxidation of activated carbon by dry and wet methods surface chemistry and textural modifications. Fuel Process. Technol. (2010). https://doi. org/10.1016/j.fuproc.2010.07.018

53. Figueiredo, J.L., Pereira, M.F.R., Freitas, M.M.A., Órfão, J.J.M.: Modification of the surface chemistry of activated carbons. Carbon N. Y. (1999). https://doi.org/10.1016/S0008-6223(98)00333 $-9$

54. Calo, J.M., Cazorla-Amorós, D., Linares-Solano, A., Román-Martínez, M.C., Salinas-Martínez De Lecea, C.: The effects of hydrogen on thermal desorption of oxygen surface complexes. Carbon N. Y. (1997). https://doi.org/10.1016/S0008-6223(96)00173-X

Publisher's Note Springer Nature remains neutral with regard to jurisdictional claims in published maps and institutional affiliations.

\section{Affiliations}

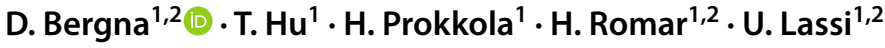

1 Research Unit of Sustainable Chemistry, University of Oulu, P.O. Box 3000, 90014 Oulu, Finland
2 Unit of Applied Chemistry, University of Jyvaskyla, Kokkola University Consortium Chydenius, Talonpojankatu 2B, 67100 Kokkola, Finland 